\title{
Update on obstructive sleep apnea and its relation to COPD
}

This article was published in the following Dove Press journal:

International Journal of COPD

8 April 2014

Number of times this article has been viewed

\section{Brian Mieczkowski Michael E Ezzie \\ Division of Pulmonary, Allergy, Critical Care and Sleep Medicine, Ohio State University, Wexner Medical Center, Columbus, $\mathrm{OH}$, USA}

\begin{abstract}
Chronic obstructive pulmonary disease (COPD) is a common and preventable lung disease that affects millions of people in the United States. Sleep disorders including obstructive sleep apnea (OSA) are also common. It is not surprising that many people with COPD also suffer from OSA. This relationship, however, puts people at risk for more nocturnal desaturations and potential complications related to this, including pulmonary hypertension and heart rhythm disturbances. This update focuses on the physiology of sleep disturbances in COPD as well as the clinical implications of OSA in COPD.
\end{abstract}

Keywords: sleep, chronic obstructive pulmonary disease, nocturnal hypoxemia, obstructive sleep apnea

\section{Introduction}

The burden of chronic obstructive pulmonary disease (COPD) is increasing, and new guidelines focus on symptom control and the impact of comorbid conditions. ${ }^{1}$ To this point, nocturnal COPD symptoms have been reported in a significant number of patients and may affect sleep. Klink et al surveyed patients and found nocturnal cough and wheezing resulted in 53\% of the patients reporting difficulty initiating or maintaining sleep, and $23 \%$ reporting excessive daytime sleepiness. ${ }^{2}$ In addition, several studies have shown that sleep quality is worse in people with COPD compared to healthy individuals..$^{3-5}$ Beyond symptoms, there are nocturnal alterations in ventilation and gas control in patients with COPD. The result for patients with significant daytime hypoxemia and hypercapnia may be more profound nocturnal changes in hypoxemia, especially during rapid eye movement (REM) sleep. ${ }^{6}$ In addition to increased nocturnal symptoms, poor sleep quality, and effects on gas exchange, there are a number of COPD patients who may also have comorbid obstructive sleep apnea (OSA) (Figure 1).

OSA is a common medical condition of increasing recognition in the United States and internationally as well. OSA is a condition characterized by increased upper airway resistance associated with an intermittent decrease or absence of inspiratory air flow, often causing arousals during sleep. It has been estimated that up to one in five adults in North America have some degree of OSA, with the prevalence of OSA increasing with age. ${ }^{7}$ Although it is typically thought of as a condition affecting men, the prevalence of OSA among women is about $10 \%$. Furthermore, the sex disparity of OSA ends around age 55 with a sharp rise among postmenopausal women. ${ }^{8-11}$ In addition to age, obesity is a major risk factor for developing OSA, and modest changes in body weight can dramatically affect the severity of OSA. ${ }^{7,12}$ The incidence of OSA in the 


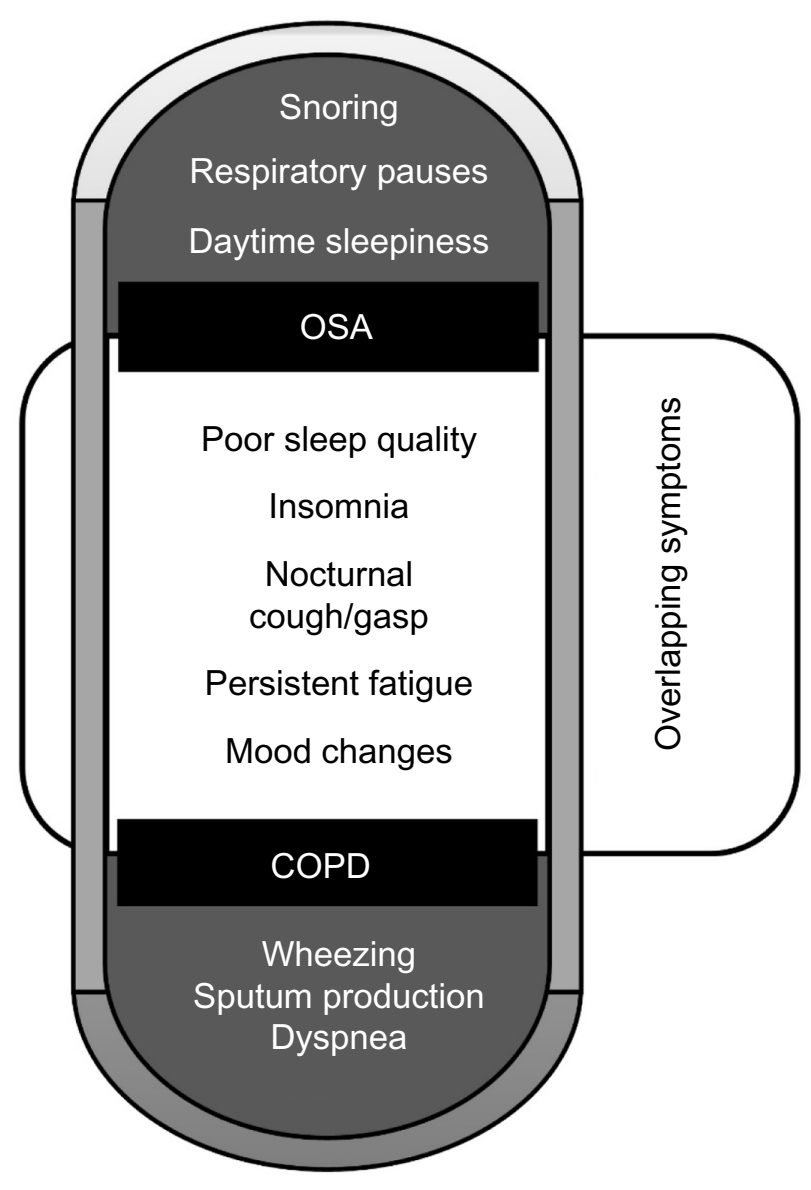

Figure I Cardinal symptoms of COPD and OSA.

Note: The common symptoms of COPD and OSA are noted with potential overlapping symptoms highlighted in the center.

Abbreviations: COPD, chronic obstructive pulmonary disease; OSA, obstructive sleep apnea.

United States parallels the increased incidence of obesity and is often a confounding factor in observational studies of OSA. Of note however, obesity is a less important risk factor for OSA among the elderly with significantly diminished effect after age 70 to 80 years. ${ }^{13}$ As the overall incidence of OSA has increased over the past 20 years, its connection to general health, quality of life, and other medical conditions has emerged. ${ }^{7} 14$ In particular, a synergistic relationship between OSA and COPD has been described and is often referred to as overlap syndrome (Figure 2). ${ }^{15}$

\section{Overlap syndrome}

The association between COPD and OSA is not fully understood, and large population studies have reported conflicting data regarding an increased prevalence of OSA among patients with COPD compared to the general population. ${ }^{16-21}$ It has been noted that approximately $11 \%$ of patients with OSA have airflow limitation on spirometry. ${ }^{18}$ The largest study to date, the Sleep Heart Health study, did

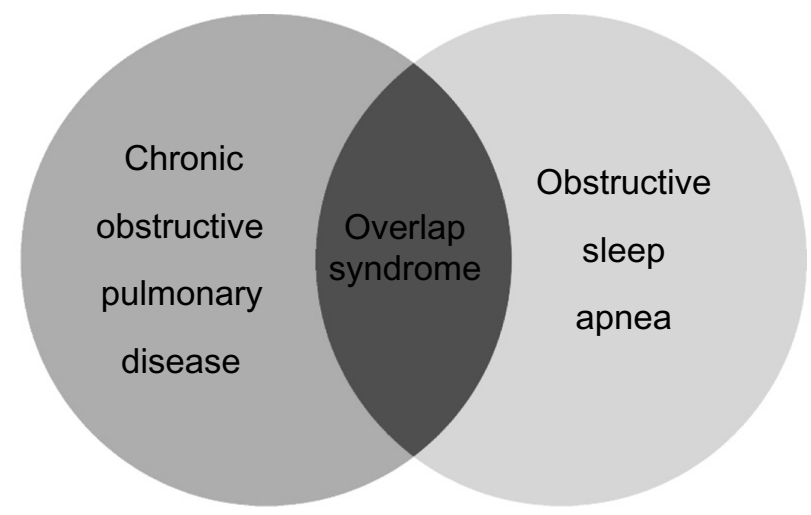

Figure 2 Overlap syndrome.

Note: The overlap syndrome is the synergistic relationship between coexisting chronic pulmonary disease and obstructive sleep apnea.

not find an increased prevalence of OSA among patients with mild airflow limitation defined by a forced expiratory volume in one second $\left(\mathrm{FEV}_{1}\right)$ to forced vital capacity ratio of less than $70 \%{ }^{19}$ In those with mild airflow obstruction without an elevated respiratory disturbance index (RDI), there was no increase in sleepiness as measured by the Epworth Sleepiness Scale. ${ }^{22}$ However, patients with airflow obstruction and an RDI greater than 10 had higher Epworth sleepiness scores, lower total sleep time and sleep efficiency, and were more likely to have desaturations than those with airflow obstruction or an elevated RDI in isolation. ${ }^{19}$ The major limitation of this study was that most subjects had mild airflow obstruction. When compared to patients with either COPD or OSA alone, the patients that had these two conditions simultaneously displayed more profound oxygen desaturations during sleep as well as worse daytime hypoxemia and hypercapnia. ${ }^{18,19}$ There are potentially several downstream health consequences of this, including an increased overall mortality among patients with overlap syndrome than either condition alone, most commonly due to cardiovascular disease. ${ }^{23,24}$

\section{Overlap syndrome physiology}

There are three broad aspects of the respiratory physiology of sleep that account for the physiologic derangements seen in the overlap syndrome. The increase in upper airway resistance, classically seen in OSA, has impact on thoracic physiology and the effectiveness of gas exchange distal to the site of airway narrowing. Thoracic structure and, in particular, the effect on diaphragmatic effort and ability to maintain adequate ventilation during sleep are intimately associated with both COPD and OSA. Finally, changes in central mediators of respiratory effort impact compensatory mechanisms for these conditions. 


\section{Upper airway resistance}

There are two main regions in the upper airway that are responsible for increased airway airflow resistance during sleep, the base of the tongue and the soft palate. These structures approximate the posterior wall of the pharynx resulting in anterior-posterior narrowing, especially prominent in a supine body position. In addition, lateral pharyngeal wall intrusion occurs due to negative intraluminal pressure during inspiration and a reduction in pharyngeal dilator muscle tone, resulting in circumferential airway collapse. Oropharyngeal crowding from redundant soft tissue seen among obese individuals and people from certain ethnic backgrounds predisposes them to obstructive sleep apnea. ${ }^{25-27}$ In a similar way, mucosal inflammation such as chronic rhinitis, which is often seen in cigarette smoking, may contribute to this phenomenon. ${ }^{28-30}$ The normal circadian change in airway caliber also contributes to a mild bronchoconstriction during sleep and an increase in airway resistance. ${ }^{31}$ Finally, increased diaphragmatic and abdominal muscle effort is required to overcome the upper airway resistance and maintain adequate airflow to the lower respiratory tract. This can be particularly difficult in patients with comorbid intrathoracic airway resistance, due to chronic inflammation and hyperinflation, and increased dead space ventilation at baseline.

With regards to sleep quality in COPD, the typical cough reflex of patients with chronic bronchitis and emphysema is reduced during sleep..$^{32}$ In patients with chronic bronchitis or bronchiectasis, airway clearance of excess mucus can be particularly important. Accumulation of airway secretions may lead to mucous plugging and a reduction in alveolar ventilation. There is no data, however, to suggest that mucolytic agents benefit patients with COPD or overlap syndrome, and recent guidelines do not recommend routine use of mucolytic agents. ${ }^{1}$

\section{Thoracic respiratory physiology}

In addition to upper airway luminal changes, thoracic respiratory physiology is an important aspect of sleep and the overlap syndrome. Alterations in minute ventilation and functional residual capacity (FRC) occur in both non-REM and REM sleep, but are more profound within REM sleep. Despite a decrease in metabolic activity during sleep, it is normal to have an increase in the partial pressure of carbon dioxide $\left(\mathrm{pCO}_{2}\right)$ of $2-10 \mathrm{mmHg}$ due to a reduction in tidal volume during non-REM sleep and a rapid-shallow breathing pattern within REM sleep. ${ }^{33,34}$ In normal individuals, a reduction in ventilation by approximately $40 \%$ occurs during REM compared to daytime breathing. ${ }^{33,35}$ This can have important consequences for individuals who have difficulty with alveolar ventilation due to hyperinflation and increased dead space ventilation. The FRC is the particular lung volume that is determined by the opposing elastic recoil forces of the thoracic wall and the lungs and often acts as an oxygen reservoir for the lungs. Body position during sleep, supine or lateral recumbent, creates external thoracic restriction. Attenuation of chest wall muscle tone, especially seen in REM sleep, reduces the outward elastic force of the thorax. These two conditions cause a reduction in the FRC and, in combination with reduced tidal volume during sleep, result in hypoventilation and decreased oxygen partial pressure $\left(\mathrm{pO}_{2}\right)$ levels, even among normal subjects.

This process can be accentuated in patients with COPD and hyperinflation. As lung volumes increase from hyperinflation or air-trapping, the curvature of the diaphragm flattens. Diaphragmatic flattening leads to diminished excursion and efficiency, creating an increased dependence on compensatory mechanisms such as accessory muscle use (Figure 3 ). The skeletal muscle atonia that occurs during REM sleep requires that respiratory efforts are again dependent on the less functional diaphragm. In addition to this, the typical REM-related rapid-shallow breathing pattern increases dead-space ventilation, further contributing to a reduction in alveolar ventilation. This is the major cause for the profound oxygen desaturations observed during sleep in patients with COPD and overlap syndrome.

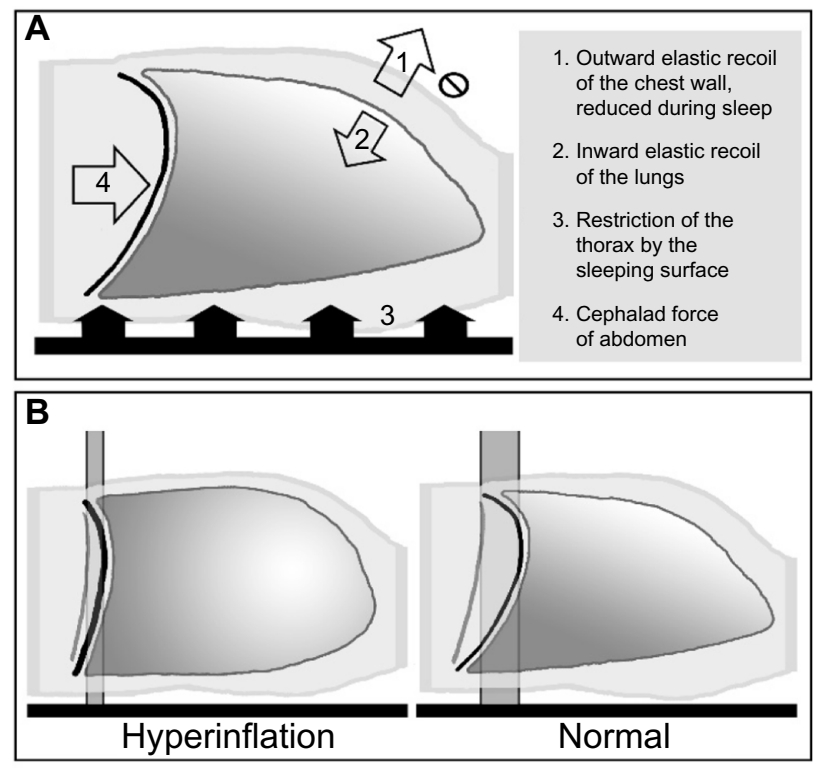

Figure 3 Thoracic physiology during supine sleep.

Notes: Forces effecting thoracic function and functional residual capacity $(\mathbf{A})$, and reduction in diaphragm excursion among patients with hyperinflation (B). 


\section{Central respiratory drive}

The final component of respiratory physiology that has important consequence in COPD and overlap syndrome during sleep is the neurochemical response of the respiratory cycle. During wakefulness, the central drive to breathe is affected by both hypercapnia and hypoxemia. During sleep these responses are blunted, allowing for more profound hypoxia and hypercapnia than observed while awake. ${ }^{33,35,36}$ The ventilatory and arousal response during sleep has been observed to be driven primarily by hypercapnia rather than hypoxemia. Arousal response to hypoxemia can be reduced as much as two-thirds in REM sleep. In experimental data, patients were observed to have a decrease in oxygen saturation into the $70 \%$ range without an arousal response. ${ }^{33,36,37}$ Conversely, small alterations in $\mathrm{pCO}_{2}$ can lead to an increase in minute ventilation. ${ }^{38,39}$

\section{Effects on nocturnal hypoxemia}

In severe COPD, oxygen saturations may decrease by $40 \%$ during REM sleep and up to a $20 \%$ decrease during nonREM sleep. ${ }^{40}$ As stated previously, this is likely a result of increased physiologic dead space during sleep in COPD, along with a more profound decrease in alveolar ventilation at low tidal volumes compared to healthy individuals. Another key aspect of the significant nocturnal desaturations observed in COPD and overlap syndrome is related to oxygen tension and its dissociation from hemoglobin. Oxygen dissociation from hemoglobin is driven by many physiologic parameters. The baseline blood oxygen tension at rest is an influential factor based on the oxyhemoglobin dissociation curve. In a subject with normal oxygen tension, the slope of the oxygen dissociation curve is shallow and thus changes in $\mathrm{pO}_{2}$ have less effect on measured oxygen saturation. As one moves along the curve towards lower oxygen tension, the slope increases dramatically. In patients with COPD with a reduced baseline $\mathrm{pO}_{2}$, the starting point is along a steeper slope, and small changes in $\mathrm{pO}_{2}$ will have a more profound effect on the oxygen saturation, as shown in Figure 4. The blunted neurochemical response, as well as a reduced muscular and ventilatory compensatory capability in patients with COPD and overlap syndrome may contribute to the profound oxygen desaturations observed in sleep.

\section{Cigarette smoking}

An important consideration for the evaluation of sleep quality and sleep-disordered breathing with COPD is the effect of cigarette smoking on each of these conditions. Cigarette smoking is the most important risk factor for the development

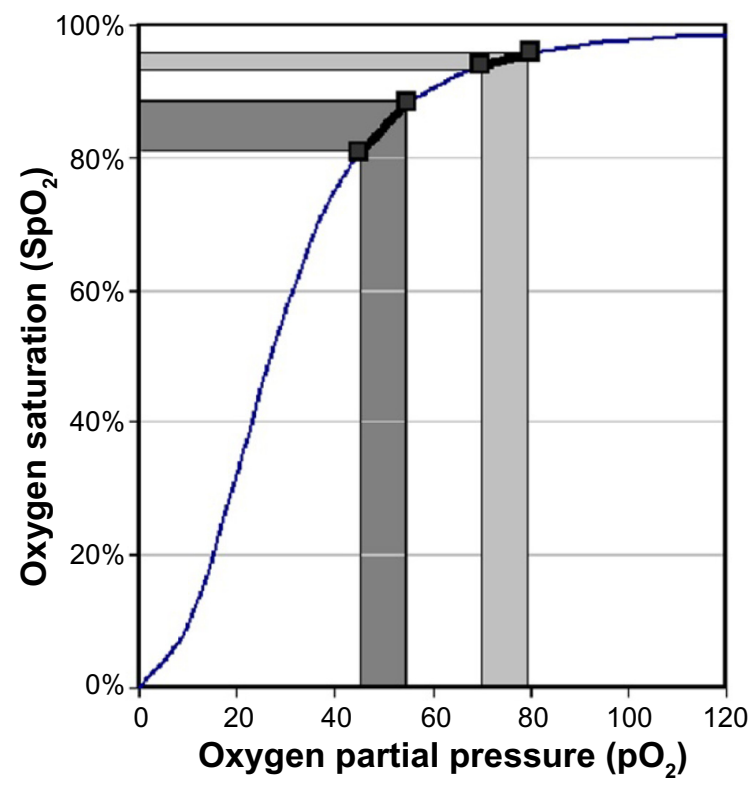

Figure 4 Oxyhemoglobin dissociation curve.

Notes: For an equal 10 point change in the oxygen partial presure $\left(\mathrm{pO}_{2}\right)$, there is a greater oxygen desaturation when the baseline $\mathrm{pO}_{2}$ is lower (light gray baseline: $80 \mathrm{mmHg}$ has a $2 \%$ desaturation; dark gray baseline: $55 \mathrm{mmHg}$ has an $8 \%$ desaturation).

Abbreviation: $\mathrm{SpO}_{2}$, oxygen saturation.

of COPD in the United States and has significant impact on sleep. Also, many patients with COPD continue to smoke cigarettes despite the health consequences that are already realized. Ongoing cigarette smoke exposure is associated with both upper and lower respiratory tract irritation and mucosal inflammation. Augmented nasal airflow resistance through increased mucosal edema and secretions is found in patients that actively smoke cigarettes and is an independent risk factor for snoring. ${ }^{28,30,41,42}$ Despite this, the association between smoking and OSA is not as clear. Some observational studies have shown an increased prevalence of OSA among active cigarette smokers compared to former and never smokers, ${ }^{43}$ but a large cross-sectional study that included 3,509 patients specifically looking at this relationship did not support smoking as an independent risk factor for developing OSA. ${ }^{44}$

Nicotine, the major component of tobacco smoke, was once purposed as a treatment for sleep-disordered breathing. Nicotine increases the activity of the pharyngeal dilator muscles including the genioglossus muscle via the hypoglossal nerve and, to a lesser extent, the diaphragm via phrenic nerve stimulation. ${ }^{45}$ Nicotine also has central effects on respiratory drive and reduction of REM stage sleep. ${ }^{45,46}$ A trial with short-acting orally absorbed nicotine did show a reduction in the frequency and duration of obstructive and mixed apneas in patients with OSA, but only for the first hours 
of sleep. ${ }^{47}$ Subsequent studies with continuously absorbed oral and transdermal nicotine patches did not show a reduction in the apnea-hypopnea index (AHI). ${ }^{46,48}$ Furthermore, cigarette smoking has been independently associated with increased sleep latency, arousal frequency, and lighter stage sleep. ${ }^{49}$ This is thought to be due to the central stimulating effects of nicotine and nocturnal nicotine withdrawal, coined "nocturnal sleep-disturbing nicotine craving". ${ }^{50}$ As a result, active smokers report worse sleep quality and greater daytime somnolence. ${ }^{51-53}$

Smoking cessation can have its own sleep disturbances as part of the withdrawal syndrome. Smoking cessation has been associated with increased arousal frequency and poorer sleep quality. This impairment of sleep has been associated with decreased abstinence rates. ${ }^{54}$ Another hindrance to smoking cessation is the potential for weight gain as measured in Quitline surveys. ${ }^{55} \mathrm{~A}$ cohort of 768 former smokers from the National Health and Nutrition Examination Survey I database were surveyed for weight gain following smoking cessation, and it was found that although the mean weight gain was 2.8 kilograms for men and 3.8 kilograms for women, almost $10 \%$ of men and $13 \%$ of females gained more than 13 kilograms. ${ }^{56}$ Peppard et al found an increase of $10 \%$ above stable body weight was associated with a $32 \%$ increase in AHI and a six-fold increase in the odds of developing moderate to severe OSA. ${ }^{12}$

\section{Consequences of overlap syndrome}

Patients with COPD and OSA often report decreased sleep quality to their treating providers. The reductions in total sleep time and sleep efficiency observed in patients with COPD have been associated with the degree of hyperinflation and nocturnal symptoms such as cough. ${ }^{57,58}$ In a study of 24 patients with COPD, the patients spent $22.4 \%$ of the mean total sleep time in relative desaturation, and arousals from sleep were associated with these periods of desaturation. When the patients were placed on supplemental oxygen to eliminate desaturations, there was no effect on the arousal index. ${ }^{3}$ The Sleep Heart Health Study, however, found that among the 1,138 patients with mild COPD alone, sleep was only minimally disturbed..$^{19}$ They did note that there was an increased odds ratio of 1.9 for nocturnal oxygen desaturation, with an $\mathrm{FEV}_{1}$ of less than $65 \%$ predicted and greater desaturations with comorbid OSA. ${ }^{19}$

It has been shown that patients with overlap syndrome report worse sleep quality than either condition alone. This was primarily due to an increase in sleep disturbances and arousals leading to a fragmented sleep pattern. ${ }^{19}$ In a study of 30 patients with overlap syndrome, the decrease in sleep efficiency correlated with the degree of hyperinflation rather than the AHI or nocturnal hypoxemia. ${ }^{58}$ This is further supported by improvements in total sleep time and sleep efficiency observed in patients successfully undergoing lung volume reduction surgery (LVRS) ${ }^{59}$ Assessments of daytime functioning among patients with OSA reveal that impaired alertness, attention, executive functioning, and memory were most strongly associated with nocturnal desaturations rather than the degree of the AHI. ${ }^{60,61}$ More complex psychological symptoms of somatization, obsession-compulsion, depression, anxiety, and hostility are associated with the presence of OSA and the degree of daytime sleepiness, but may not be associated with severity of the AHI or oxygen desaturations. ${ }^{62}$ In a similar trend, symptoms of depression and anxiety are commonly found among patients with COPD, even with a mild reduction in the $\mathrm{FEV}_{1} \cdot{ }^{63,64}$

\section{Cardiopulmonary consequences}

The repeated and prolonged nocturnal hypoxemia observed in overlap syndrome may have an association with the development of cardiovascular consequences such as pulmonary hypertension and recurrent cardiac arrhythmias. Several studies have shown that the risk for having pulmonary hypertension with OSA is increased with underlying airflow obstruction, chronic hypoventilation or hypoxemia, and the severity of obesity ${ }^{65-69}$ Without these comorbid conditions, pulmonary hypertension is not common, even in severe OSA alone. ${ }^{68,69}$ Chaouat et al demonstrated that patients with overlap syndrome have increased daytime pulmonary vascular resistance and lower daytime oxygen saturations compared to patients with OSA alone. ${ }^{18}$ In addition, evidence of increased right ventricular remodeling on thoracic imaging was recently shown among patients with overlap syndrome compared to COPD alone. ${ }^{70}$

Patients with overlap syndrome may also be at risk for increased heart rhythm disturbances. There is a noted increase in premature ventricular contractions in patients with COPD and nocturnal desaturations. ${ }^{71}$ In addition, OSA has been shown to be a risk factor for recurrent atrial fibrillation following ablation, but the association between untreated OSA and new-onset atrial fibrillation has been debated due to the confounding variable of obesity. ${ }^{72-76}$ A study of 2,873 patients showed an increased incidence of new-onset atrial fibrillation observed among patients with overlap syndrome compared to those with COPD and OSA alone. ${ }^{77}$ It was felt that repeated hypoxemia, cardiac remodeling, and alterations of cardiopulmonary pressure measures may be contributing factors. 
Importantly, for control of COPD symptoms, the COPD exacerbation rate appears to be increased among overlap syndrome patients compared to COPD alone. In a study comparing 213 patients with untreated overlap syndrome with 210 patients with COPD alone, the incidence of exacerbations requiring hospitalization was $61.4 \%$ versus $39.5 \%$, respectively, despite similar degrees of obstruction and medical therapy. All-cause mortality was also higher in the untreated overlap syndrome group compared to COPD alone, most commonly due to a cardiovascular condition. Both exacerbation rate and mortality were improved with continuous positive airway pressure (CPAP) therapy in this study. ${ }^{24}$

\section{Overlap syndrome mortality}

COPD is now the third leading cause of death in the United States according to the Centers for Disease Control. ${ }^{78}$ Prognosis for patients with COPD can be evaluated with multidimensional indexes that include body mass, degree of airflow obstruction, dyspnea scores, and walking distance. ${ }^{79}$ Studies now show that for patients with OSA, a reduced $\mathrm{FEV}_{1}$ or a history of smoking may lead to increased mortality. ${ }^{23,80,81}$ In one study, there was a seven-fold increase in the risk of death in OSA patients with COPD ${ }^{80}$ Comorbid OSA, when untreated, may also contribute to increased risk of death in patient with COPD, as described by Marin and colleagues. ${ }^{24}$ The mechanisms that result in worsening outcomes for patients with the overlap syndrome are not yet understood. Several potential areas of concern are the increased cardiovascular consequences described earlier as well as increased exacerbations. These are areas that continue to deserve investigation.

\section{Screening and diagnosis}

A challenge for providers is that patients with chronic lung diseases often underreport daytime symptoms of sleepiness despite reporting poor sleep quality. ${ }^{82}$ General consensus statements suggest screening for sleep disordered breathing in COPD patients who complain of symptoms typically associated with sleep-disordered breathing such as excessive daytime somnolence and frequent nocturnal arousals from sleep. ${ }^{1}$ Additionally, it has been suggested that patients with COPD who develop morning headaches following nocturnal oxygen supplementation should undergo a diagnostic polysomnogram. ${ }^{83}$ The American Thoracic Society/European Respiratory Society recommend a screening polysomnogram in patients with mild to moderate airflow obstruction and evidence of pulmonary hypertension..$^{84} \mathrm{~A}$ recent meta-analysis of 42 studies investigating clinic predictors of OSA showed the most reliable symptom for OSA screening was the presence of nocturnal choking or gasping with a likelihood ratio of 3.3. Of note, the investigators found that a history of snoring was a poor predictor of OSA. ${ }^{85}$ Conversely, patients with OSA who have respiratory complaints typical of COPD and the presence of risk factors for COPD, most prominently cigarette smoking, should have a screening spirometry test performed. If there is clinical concern for nocturnal desaturations based on daytime oxygen saturations that are less than $93 \%$, this may be evaluated by nocturnal oximetry. However, the utility of overnight oxygen saturation measurements in suggesting OSA in COPD is quite limited. Nocturnal oximetry may be more useful for evaluating the effectiveness of nocturnal oxygen therapy.

The presence of OSA is determined by the frequency of apnea and hypopnea events per hour of sleep (the AHI) that a person has on a polysomnogram. While the definition of apnea in adults is widely accepted as the absence of airflow for at least 10 seconds, the definition of hypopnea is not. The two common scoring criteria for hypopnea are the reduction of airflow for at least 10 seconds with either a $4 \%$ oxygen desaturation or a $3 \%$ oxygen desaturation with subsequent arousal.

A common alternative to the AHI for determining the presence and severity of OSA is based on the RDI. Prior to 2008 , the term RDI was equivalent to the current definition of AHI. Since 2008 and currently, there are two accepted definitions of RDI. Unattended overnight polysomnograms performed in an ambulatory setting (also known as "portable" or "home" sleep studies) have been a common modality for screening for OSA in high risk patient populations. These studies utilize a limited number of channels, and exact sleep time and arousals from sleep as determined by electroencephalography are often not available. Index time is utilized in place of sleep time, and this is the recording time of the study minus any amount of time when surrogate markers of wakefulness are present. The RDI in this situation is defined by the number of apnea and hypopnea ( $4 \%$ oxygen desaturation definition) events per index time. The alternate definition includes respiratory-event related arousals (RERAs) in addition to apnea and hypopnea events per hour of sleep. RERAs are events of increasing respiratory effort leading to an arousal without an associated oxygen desaturation. Although RERAs represent disruptions in sleep and can lead to daytime sleepiness, they do not contribute to the diagnosis of OSA. Intermittent nocturnal oxygen desaturations observed in patients with COPD may often be independent of increased upper airway resistance or collapse. There must be careful 
evaluation of the airflow pattern to avoid over-scoring these events as hypopneas rather than oxygen desaturations. The American Academy of Sleep Medicine (AASM) defines OSA by at least five events per hour of sleep with associated symptoms such as daytime sleepiness, respiratory pauses during sleep, or gasping arousals. ${ }^{86}$ It is important to note that research trials over time have varied in the cutoff points for defining sleep apnea with a range of an AHI of five events per hour with symptoms present to 20 events per hour.

\section{Other sleep apnea syndromes}

While overlap syndrome is the combination of COPD and OSA, there are other types of sleep-disordered breathing that are less commonly seen but can be present in patients with COPD. Central sleep apnea (CSA) and complex sleep apnea (CompSA) are two broad categories of sleep apnea, but data on the association and combined consequences with COPD are lacking. CSA is repetitive cessation of breathing without associated respiratory effort during sleep due to hyperventilation with hypocapnia-associated respiratory pauses or chronic hypoventilation. Hyperventilation is the mechanism for primary CSA, high altitude central apnea, or CSA associated with congestive heart failure (CHF), while chronic hypoventilation CSA is commonly associated with neuromuscular disease and chronic opiate medication use. In 2012, the AASM released a meta-analysis and practice guidelines for the treatment of adults with the various CSA syndromes, wherein treatment often consists of maintenance of adequate ventilation via CPAP or bilevel positive airway pressure (PAP) therapy. ${ }^{87}$

CompSA refers to the emergence of central apneas upon treatment of underlying OSA with PAP therapy. Three purposed mechanisms for the development of CompSA have been established, including increased loop gain, relief of OSA related hypercapnea, and induction of stretch receptors. ${ }^{88-91}$ Among patients who develop CompSA, approximately half will resolve after 8 weeks with CPAP therapy alone. ${ }^{92}$ The remainder will need alternative strategies that support adequate nocturnal ventilation.

\section{Treatment of overlap syndrome}

Literature regarding the effects of various treatment modalities in patients with overlap syndrome compared to either condition alone is limited. As such, treatment for overlap syndrome should focus on maximizing the therapeutic benefit of each condition and focus on interventions that have shown benefit in both conditions. The goal of therapy is both improvement in objective data such as reduction in sleep fragmentation, exacerbation rate, hospitalization frequency, and mortality; and subjective data including daytime functioning, quality of life, and sleep quality. It is important to acknowledge that coexisting cardiovascular conditions are common to both COPD and OSA and is the leading cause of death among patients with overlap syndrome. ${ }^{24}$

Improvement in daytime symptom control with best practices as recommended in COPD guidelines would likely translate to improved sleep. A number of pharmaceutical agents have been evaluated in COPD and OSA for nocturnal benefit. Theophylline has been studied in COPD with conflicting results on the effect on sleep quality. ${ }^{93-95}$ Theophylline has also been studied in patients with OSA alone and has shown varying improvement in the $\mathrm{AHI},{ }^{96,97}$ but potentially at the consequence of significantly greater disruption in sleep quality. ${ }^{97}$ Anticholinergics have been shown to improve nocturnal hypoxemia and sleep quality. ${ }^{98,99}$ Salmeterol, when compared to placebo, did not show an improvement in AHI or sleep quality in patients with OSA alone. ${ }^{100}$ The use of beta agonist medications, both short- and long-acting formulations, has been shown to improve sleep quality among patients with stable COPD when used alone and in combination with an inhaled corticosteroid. ${ }^{101}$ One study had a trend towards improvement in insomnia in patients with stable COPD when a beta agonist was used within 2 hours of bedtime. ${ }^{102}$

Systemic corticosteroid administration is the cornerstone of treatment for acute exacerbations of COPD, demonstrating improvement in the rate of lung function recovery, dyspnea, and hospital length of stay, although the treatment dose and duration can vary widely in the community. ${ }^{1}$ Adverse side effects of systemic corticosteroid are commonly reported and are often linked to the cumulative dose and duration of use. Among the major trials assessing the efficacy of systemic corticosteroids during exacerbations, limited data was reported about sleep disturbances or weight changes. ${ }^{103-106}$ A Cochrane Review in 2005 reported an odds ratio of developing insomnia among patients treated with systemic corticosteroid for an acute exacerbation of COPD of 3.53 $(P=0.001) .{ }^{103}$ Aaron et al compared 74 patients treated with prednisone $40 \mathrm{mg}$ daily for 10 days with 73 patients treated with placebo. ${ }^{107}$ This study found an increased rate of insomnia among the corticosteroid arm, with nearly half of these patients reporting insomnia ( $48 \%$ versus $21 \%, P=0.001)$. In addition, weight gain was reported by $13 \%$ of the patients who received corticosteroids compared to $1 \%$ patients who did not. Significant and persistent weight gain has been observed with chronic and recurrent courses of systemic corticosteroids in a myriad of inflammatory conditions. 
Steroid-induced skeletal muscle atrophy is also a known side effect of systemic corticosteroids, especially in chronic use. Decramer et al found significant respiratory and quadriceps muscle weakness among the patients with a cumulative daily dose of $4.3 \mathrm{mg}$ of methylprednisolone from steroid "burst" treatments over a 6-month period for exacerbations of their COPD. ${ }^{108}$ However, this same acquired weakness was not observed in a study of 25 patients with stable COPD who were given $30 \mathrm{mg}$ of prednisolone daily for 2 weeks. ${ }^{109}$ This suggests that the combined effect of the systemic corticosteroid and an acute inflammatory state drives the development of muscular weakness. This muscular weakness can affect the previously described compensatory mechanisms patients with COPD and overlap syndrome utilize during sleep. Sleep disruption and weight gain have not been commonly reported with the use of inhaled corticosteroids in COPD.

Recommendations for nonpharmacologic treatment of COPD support the use of pulmonary rehabilitation. Another nonpharmacologic therapy for COPD is LVRS. ${ }^{110}$ While few patients qualify for LVRS, this treatment has also shown benefits with improved sleep time and sleep efficiency as well as improvements in nocturnal desaturations in those undergoing LVRS compared to medical therapy alone. ${ }^{59}$ If a sleep aid is needed in patients with COPD, there is evidence that zolpidem does not decrease the respiratory drive or minute ventilation in COPD patients. ${ }^{111}$

\section{Exercise and dietary modifications}

Behavioral modifications including exercise programs, dietary alteration, and therapeutic compliance are the cornerstones of treating many medical conditions. Structured exercise has been investigated in both COPD and OSA. There are many health gains that have been reported for COPD patients with pulmonary rehabilitation, including improving dyspnea scores, mood indexes, quality of life measurements, daily functioning and hospital admission frequency. ${ }^{112}$ An important feature of structured exercise programs is muscle reconditioning and efforts to increase skeletal muscle mass. Muscle wasting and low body mass index (less than $21 \mathrm{~kg} / \mathrm{m}^{2}$ ) correlate with decreased functional state, quality of life, and survival among patients with COPD. ${ }^{79,113}$ There is evidence to suggest that obesity in patients with at least moderate COPD may protect against hyperinflation due to thoracic wall restriction, ${ }^{114,115}$ although obesity itself can limit exercise capacity and functional mobility and contribute to risk for OSA. ${ }^{116-118}$ A recent study by Soler et al evaluated the effects of pulmonary rehabilitation on sleep quality in 64 patients with chronic lung disease undergoing an 8 week comprehensive pulmonary rehabilitation program. Poor sleep quality was reported by $58 \%$ of the patients at enrollment, and sleep quality improved by $19 \%$ using the Pittsburgh Sleep Quality Index. ${ }^{119}$

In patients with OSA, structured exercise programs between 3 and 6 months have shown improvements in AHI, independent of reduction in body mass index, functional state, and quality of life. Exercise has also resulted in improvement in daytime sleepiness and sleep quality in some studies, ${ }^{120-123}$ although no significant difference in daytime sleepiness with exercise alone has been reported. ${ }^{120}$ Treatment with CPAP has demonstrated improvement in exercise capacity among patients with OSA. ${ }^{124}$ Specifically in overlap syndrome, treatment with CPAP has demonstrated improvement in walking capacity and exercise tolerance. ${ }^{125,126}$

There are no specific dietary modifications for treating COPD, OSA, or overlap syndrome. Structured dietary programs with low calorie consumption to target body weight reduction have demonstrated reduction in AHI. ${ }^{127-129}$ Among patients who have coexisting hypertension, CHF, or pulmonary hypertension, dietary restriction of sodium is generally recommended. ${ }^{130-132}$

\section{Supplemental oxygen}

A major consequence of overlap syndrome is persistent and profound oxygen desaturation during sleep, related to hypoventilation and alterations in the neurochemical responsiveness to hypoxemia and hypercapnia detailed above. Supplemental oxygen has been used to mitigate this issue. The Nocturnal Oxygen Therapy Trial demonstrated improved survival among patients with COPD with longterm oxygen therapy, although this trial did not specifically investigate patients with nocturnal desaturations alone. ${ }^{16}$ The 2013 Global initiative for chronic Obstructive Lung Disease (GOLD) guidelines recommend that supplemental oxygen therapy be provided to patients whose oxygen saturations fall below $88 \%$ or who have a $\mathrm{PO}_{2}$ less than $55 \mathrm{mmHg}$ during wakefulness or $\mathrm{PO}_{2}$ between 55 and $60 \mathrm{mmHg}$ with evidence of pulmonary hypertension, CHF or polycythemia. ${ }^{1}$ The goal of oxygen administration is to increase the baseline $\mathrm{PO}_{2}$ to $60 \mathrm{mmHg}$ or pulse oximeter reading to $90 \%$ during the day. Nocturnal supplemental oxygen use in patients with OSA has had mixed clinical improvement, although several trials have demonstrated a reduction in overall AHI and nocturnal desaturations with supplemental oxygen, ${ }^{133,134}$ others have not. ${ }^{135,136}$ One trial showed a reduction in bradycardia associated with apnea events. ${ }^{133}$ Despite this, evidence to support the clinical effectiveness of consistently improving 
sleep architecture, total sleep time, daytime functioning, and daytime alertness is lacking. ${ }^{134,135}$

\section{Positive airway pressure}

The mainstay of treatment for patients with OSA and overlap syndrome is positive airway pressure using either CPAP or bilevel positive airway pressure (PAP). These modalities act as a pneumatic stent to overcome upper airway closure during sleep and effectively reduce the AHI. The reduction in the AHI and improvement in sleep quality in patients with OSA treated with PAP is greater compared to supplemental oxygen alone ${ }^{136}$ and is recommended by the AASM. ${ }^{86}$ In addition to improvement in sleep quality and daytime sleepiness, treatment of OSA with CPAP has shown important beneficial effects on secondary cardiovascular conditions including systemic hypertension, pulmonary arterial pressure, and recurrent atrial fibrillation after ablation. ${ }^{86}$ The need for bilevel PAP for nocturnal noninvasive ventilation is often determined by persistent hypoventilation leading to hypoxemia despite resolution of obstructive events with CPAP.

In patients with COPD and chronic hypercapnia, nocturnal noninvasive ventilation has yielded mixed results in quality of life and daytime function. ${ }^{1,137,138}$ A recent Cochrane Review failed to demonstrate consistent improvement in gas exchange, health-related quality of life, and lung function at 3 and 12 months of nocturnal noninvasive ventilation in COPD alone. ${ }^{139}$ A trial utilizing nocturnal noninvasive ventilation with long-term supplemental oxygen showed improvement in survival, but excluded patients with OSA and morbid obesity. ${ }^{137}$ For patients with respiratory disease to be considered for bilevel PAP, the Centers for Medicare and Medicaid Services guidelines ${ }^{140}$ require a $\mathrm{pCO}_{2}$ of at least $52 \mathrm{mmHg}$ while using the patient's prescribed supplemental oxygen; sleep oximetry with an oxygen saturation less than $88 \%$ for at least 5 consecutive minutes while breathing oxygen at $2 \mathrm{~L}$ per minute or the patient's prescribed flow rate; and an evaluation for OSA. It is important to consider that CPAP utilizes high airflow rates to support increased airway pressure and may require additional flow rates of entrained supplemental oxygen to assure similar oxygen concentrations within the system.

There is limited data specifically addressing the treatment of overlap syndrome with PAP therapy, but it is supported by the AASM and GOLD guidelines. ${ }^{1,86}$ In small studies, treatment with CPAP among patients with overlap syndrome resulted in improved survival and decreased COPD exacerbations leading to hospitalization. ${ }^{24,141}$ A retrospective review that included 227 patients with overlap syndrome revealed that the use of CPAP also improved survival. Age was also an independent risk factor for mortality in this study and was associated with nightly duration of CPAP use. ${ }^{141}$ Treatment with CPAP has also demonstrated improvement in walking capacity and exercise tolerance among patients with overlap syndrome. ${ }^{125,126}$

\section{Clinical cases}

A 65-year-old, obese male with a 40 pack-year tobacco history as well as hypertension requiring four drugs for control presented with a postbronchodilator $\mathrm{FEV}_{1}$ of $45 \%$ predicted. His resting oxygen saturation by pulse oximeter measured $92 \%$. He used his short-acting bronchodilator up to five times per day for exertional dyspnea. He complained of daytime fatigue and sleepiness as well as morning headaches and attributed this to his age and COPD. Regarding his history, the patient had a fragmented sleep pattern and reported frequent napping. On examination he had pretibial edema. A polysomnogram was performed and showed evidence of OSA with significant desaturations as depicted in Figure 5. A CPAP titration was performed, but hypoxemia independent of apnea or hypopnea events persisted, resulting in the addition of supplemental oxygen. On follow-up consultation, he reported improvement in his fatigue, daytime sleepiness, and improved walking distance without dyspnea.

This case highlights the coexistence of OSA in a patient with COPD. The patient has poor symptom control of COPD but also has symptoms consistent with OSA, including daytime somnolence and morning headaches. Fatigue and sleepiness should not be attributed to COPD. Given the extent of symptoms and relative hypoxia by daytime pulse oximetry, a polysomnogram should be performed in similar patients to evaluate for OSA. It is important to note that when evaluating a patient with potential overlap syndrome, intermittent nocturnal oxygen desaturations may resolve with treatment of the underlying sleep apnea. Priority should be given to the treatment of OSA before instituting supplemental oxygen. When appropriate, patients with potential overlap syndrome who are already using nocturnal supplemental oxygen should initially have their polysomnogram and subsequent PAP titration study performed without supplemental oxygen. If, as in this case, PAP therapy alone does not correct the patient's nocturnal hypoxemia, the additional use of supplemental oxygen may be required to support their oxygen needs.

A second clinical case involved a 55-year-old postmenopausal female who was an active smoker with 


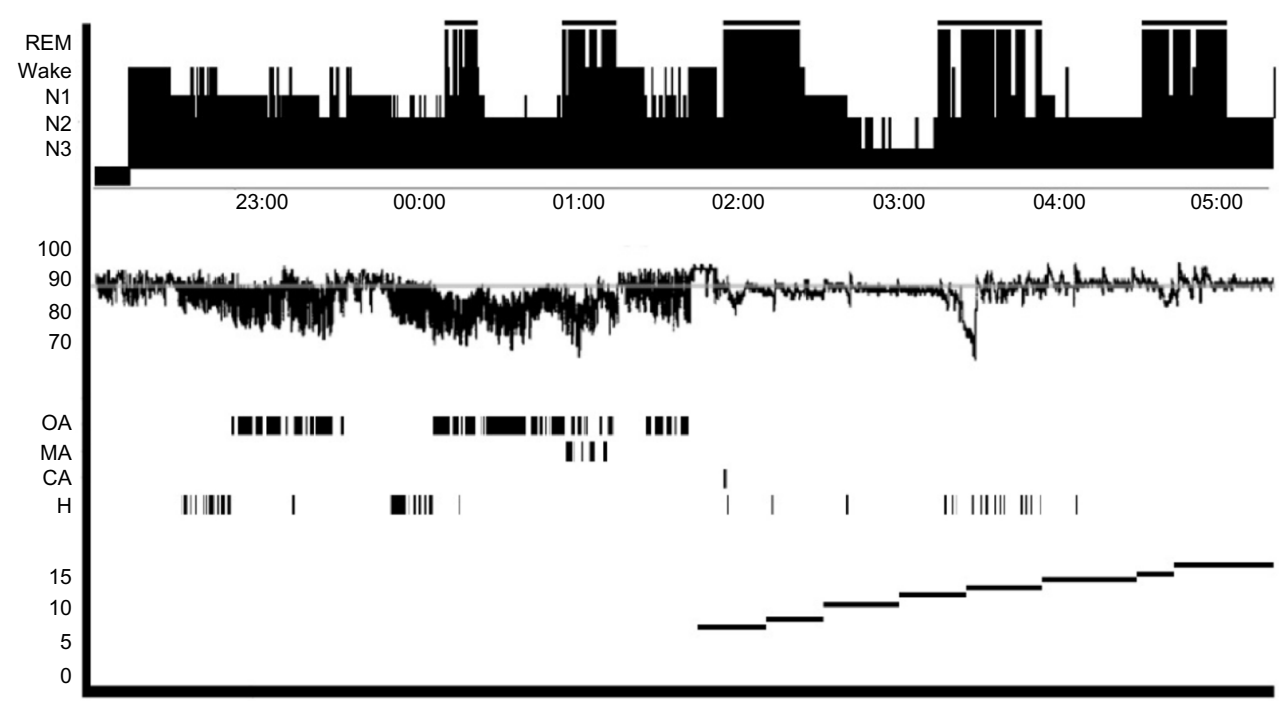

Figure 5 Overnight polysomnogram.

Notes: This summary displays a sleep stage hypnogram, oxygen saturation during the study, apnea and hyponea events, and positive airway pressure settings. Note the continued oxygen desaturations associated with REM despite reduction in apnea and hypopnea events (the gray line indicates $88 \%$ saturation).

Abbreviations: REM, rapid eye movement; NI, Sleep Stage I; N2, Sleep Stage 2; N3, Slow Wave Sleep; OA, obstructive apnea; MA, mixed apnea; CA, central apnea; H, hypopnea.

moderate COPD. She had undergone attempts at smoking cessation. She had weight gain of 18 pounds over 8 months, and she complained of new onset of daytime sleepiness and increased caffeine use. Her bed partner reported that she had frequent snoring. A polysomnogram was performed with evidence of moderate OSA. She was initiated on CPAP therapy with improvement in symptoms.

This case highlights the potential of OSA to develop in COPD patients with significant weight gain. In addition, as in this case, it is important to recognize risk factors for OSA beyond obesity such as in a female patient who has completed menopause. Symptoms may be misconstrued as COPD, but history-taking may reveal symptoms typically associated with sleep apnea including snoring, gasping efforts during sleep, fragmented sleep patterns, and daytime sleepiness. Often patients will mask symptoms of excessive daytime sleepiness with gradually increased caffeine consumption. This history can be as important as a complaint of daytime sleepiness. A polysomnogram is warranted to diagnose OSA given the change in symptoms.

\section{Conclusion}

COPD and OSA are both common conditions with a complex relationship. Attention to comorbid conditions is an important component of best practice care of the COPD patient. It is therefore important that clinicians recognize that the management of the COPD patient should include a comprehensive sleep history, including sleep hygiene and OSA. Recognition of sleep-related disturbances in patients with COPD will assist clinicians in the management of these patients and allow for improved respiratory and sleep-related quality of life.

\section{Disclosure}

The authors report no conflicts of interest in this work.

\section{References}

1. Global Initiative for Chronic Obstructive Lung Disease (GOLD). Global Strategy for the Diagnosis, Management and Prevention of Chronic Pulmonary Disease. Global Initiative for Chronic Obstructive Lung Disease; 2011. Available from: http://www.goldcopd.org/uploads/users/ files/GOLD_Report_2011_Feb21.pdf. Accessed October 1, 2013.

2. Klink ME, Dodge R, Quan SF. The relation of sleep complaints to respiratory symptoms in a general population. Chest. 1994;105(1): 151-154.

3. Fleetham J, West P, Mezon B, Conway W, Roth T, Kryger M. Sleep, arousals, and oxygen desaturation in chronic obstructive pulmonary disease. The effect of oxygen therapy. Am Rev Respir Dis. 1982;126(3): 429-433.

4. Calverley PM, Brezinova V, Douglas NJ, Catterall JR, Flenley DC. The effect of oxygenation on sleep quality in chronic bronchitis and emphysema. Am Rev Respir Dis. 1982;126(2):206-210.

5. Brezinova V, Catterall JR, Douglas NJ, Calverley PM, Flenley DC. Night sleep of patients with chronic ventilatory failure and age matched controls: number and duration of the EEG episodes of intervening wakefulness and drowsiness. Sleep. 1982;5(2):123-130.

6. Mulloy E, McNicholas WT. Ventilation and gas exchange during sleep and exercise in severe COPD. Chest. 1996;109(2):387-394.

7. Peppard PE, Young T, Barnet JH, Palta M, Hagen EW, Hla KM. Increased prevalence of sleep-disordered breathing in adults. Am J Epidemiol. Epub April 14, 2013.

8. Bixler EO, Vgontzas AN, Lin HM, et al. Prevalence of sleep-disordered breathing in women: effects of gender. Am J Respir Crit Care Med. 2001;163(3 Pt 1):608-613.

9. Dancey DR, Hanly PJ, Soong C, Lee B, Hoffstein V. Impact of menopause on the prevalence and severity of sleep apnea. Chest. 2001;120(1): $151-155$. 
10. Tishler PV, Larkin EK, Schluchter MD, Redline S. Incidence of sleep-disordered breathing in an urban adult population: the relative importance of risk factors in the development of sleep-disordered breathing. JAMA. 2003;289(17):2230-2237.

11. Young T, Palta M, Dempsey J, Skatrud J, Weber S, Badr S. The occurrence of sleep-disordered breathing among middle-aged adults. N Engl J Med. 1993;328(17):1230-1235.

12. Peppard PE, Young T, Palta M, Dempsey J, Skatrud J. Longitudinal study of moderate weight change and sleep-disordered breathing. JAMA. 2000;284(23):3015-3021.

13. Young T, Shahar E, Nieto FJ, et al; Sleep Heart Health Study Research Group. Predictors of sleep-disordered breathing in community-dwelling adults: the Sleep Heart Health Study. Arch Intern Med. 2002;162(8): 893-900.

14. Chen YH, Keller JK, Kang JH, Hsieh HJ, Lin HC. Obstructive sleep apnea and the subsequent risk of depressive disorder: a population-based follow-up study. J Clin Sleep Med. 2013;9(5):417-423.

15. Flenley DC. Sleep in chronic obstructive lung disease. Clin Chest Med. 1985;6(4):651-661.

16. Continuous or nocturnal oxygen therapy in hypoxemic chronic obstructive lung disease: a clinical trial. Nocturnal Oxygen Therapy Trial Group. Ann Intern Med. 1980;93(3):391-398.

17. Brander PE, Kuitunen T, Salmi T, Partinen M. Nocturnal oxygen saturation in advanced chronic obstructive pulmonary disease after a moderate dose of ethanol. Eur Respir J. 1992;5(3):308-312.

18. Chaouat A, Weitzenblum E, Krieger J, Ifoundza T, Oswald M, Kessler R. Association of chronic obstructive pulmonary disease and sleep apnea syndrome. Am J Respir Crit Care Med. 1995;151(1):82-86.

19. Sanders MH, Newman AB, Haggerty CL, et al; Sleep Heart Health Study. Sleep and sleep-disordered breathing in adults with predominantly mild obstructive airway disease. Am J Respir Crit Care Med. 2003;167(1):7-14.

20. O'Donoghue FJ, Catcheside PG, Ellis EE, et al; Australian trial of Noninvasive Ventilation in Chronic Airflow Limitation investigators. Sleep hypoventilation in hypercapnic chronic obstructive pulmonary disease: prevalence and associated factors. Eur Respir J. 2003;21(6): 977-984.

21. Bednarek M, Plywaczewski R, Jonczak L, Zielinski J. There is no relationship between chronic obstructive pulmonary disease and obstructive sleep apnea syndrome: a population study. Respiration. 2005;72(2): 142-149.

22. Johns MW. A new method for measuring daytime sleepiness: the Epworth sleepiness scale. Sleep. 1991;14(6):540-545.

23. Chaouat A, Weitzenblum E, Krieger J, et al. Prognostic value of lung function and pulmonary haemodynamics in OSA patients treated with CPAP. Eur Respir J. 1999;13(5):1091-1096.

24. Marin JM, Soriano JB, Carrizo SJ, Boldova A, Celli BR. Outcomes in patients with chronic obstructive pulmonary disease and obstructive sleep apnea: the overlap syndrome. Am J Respir Crit Care Med. 2010;182(3):325-331.

25. Horner RL, Mohiaddin RH, Lowell DG, et al. Sites and sizes of fat deposits around the pharynx in obese patients with obstructive sleep apnoea and weight matched controls. Eur Respir J. 1989;2(7):613-622.

26. Schwab RJ, Pasirstein M, Kaplan L, et al. Family aggregation of upper airway soft tissue structures in normal subjects and patients with sleep apnea. Am J Respir Crit Care Med. 2006;173(4):453-463.

27. Villaneuva AT, Buchanan PR, Yee BJ, Grunstein RR. Ethnicity and obstructive sleep apnoea. Sleep Med Rev. 2005;9(6):419-436

28. Young T, Finn L, Kim H. Nasal obstruction as a risk factor for sleepdisordered breathing. The University of Wisconsin Sleep and Respiratory Research Group. J Allergy Clin Immunol. 1997;99(2):S757-S762.

29. Kalpaklioğlu AF, Kavut AB, Ekici M. Allergic and nonallergic rhinitis: the threat for obstructive sleep apnea. Ann Allergy Asthma Immunol. 2009;103(1):20-25.

30. Benninger MS. The impact of cigarette smoking and environmental tobacco smoke on nasal and sinus disease: a review of the literature. Am J Rhino. 1999;13(6):435-438.
31. Hetzel MR, Clark TJ. Comparison of normal and asthmatic circadian rhythms in peak expiratory flow rate. Thorax. 1980;35(10):732-738.

32. Power JT, Stewart IC, Connaughton JJ, et al. Nocturnal cough in patients with chronic bronchitis and emphysema. Am Rev Respir Dis. 1984;130(6):999-1001.

33. Douglas NJ, White DP, Pickett CK, Weil JV, Zwillich CW. Respiration during sleep in normal man. Thorax. 1982;37(11):840-844.

34. Shepard JW Jr. Gas exchange and hemodynamics during sleep. Med Clin North Am. 1985;69(6):1243-1264.

35. White DP, Douglas NJ, Pickett CK, Weil JV, Zwillich CW. Hypoxic ventilatory response during sleep in normal premenopausal women. Am Rev Respir Dis. 1982;126(3):530-533.

36. Berthon-Jones M, Sullivan CE. Ventilatory and arousal responses to hypoxia in sleeping humans. Am Rev Respir Dis. 1982;125(6): 632-639.

37. Gothe B, Goldman MD, Cherniack NS, Mantey P. Effect of progressive hypoxia on breathing during sleep. Am Rev Respir Dis. 1982;126(1): 97-102.

38. Douglas NJ, White DP, Weil JV, Pickett CK, Zwillich CW. Hypercapnic ventilatory response in sleeping adults. Am Rev Respir Dis. 1982;126(5):758-762.

39. Hedemark LL, Kronenberg RS. Ventilatory and heart rate responses to hypoxia and hypercapnia during sleep in adults. J Appl Physiol Respir Environ Exerc Physiol. 1982;53(2):307-312.

40. Becker HF, Piper AJ, Flynn WE, et al. Breathing during sleep in patients with nocturnal desaturation. Am J Respir Crit Care Med. 1999;159(1): $112-118$.

41. Trenchea M, Deleanu O, Suţa M, Arghir OC. Smoking, snoring and obstructive sleep apnea. Pneumologia. 2013;62(1):52-55.

42. Franklin KA, Gíslason T, Omenaas E, et al. The influence of active and passive smoking on habitual snoring. Am J Respir Crit Care Med. 2004;170(7):799-803.

43. Kashyap R, Hock LM, Bowman TJ. Higher prevalence of smoking in patients diagnosed as having obstructive sleep apnea. Sleep Breath. 2001;5(4):167-172.

44. Hoflstein V. Relationship between smoking and sleep apnea in clinic population. Sleep. 2002;25(5):519-524.

45. Haxhiu MA, Van Lunteren E, Van de Graaff WB, et al. Action of nicotine on the respiratory activity of the diaphragm and genioglossus muscles and the nerves that innervate them. Respir Physiol. 1984;57(2): 153-169.

46. Davila DG, Hurt RD, Offord KP, Harris CD, Shepard JW. Acute effects of transdermal nicotine on sleep architecture, snoring, and sleepdisordered breathing in nonsmokers. Am J Respir Crit Care Med. 1994;150(2):469-474.

47. Gothe B, Strohl KP, Levin S, Cherniack NS. Nicotine: a different approach to treatment of obstructive sleep apnea. Chest. 1985;87(1): 11-17.

48. Zevin S, Swed E, Cahan C. Clinical effects of locally delivered nicotine in obstructive sleep apnea syndrome. Am J Ther. 2003;10(3): $170-175$.

49. Zhang L, Samet J, Caffo B, Punjabi NM. Cigarette smoking and nocturnal sleep architecture. Am J Epidemiol. 2006;164(6):529-537.

50. Rieder A, Kunze U, Groman E, Kiefer I, Schoberberger R. Nocturnal sleep-disturbing nicotine craving: a newly described symptom of extreme nicotine dependence. Acta Med Austriaca. 2001;28(1):21-22.

51. Wetter DW, Young TB. The relation between cigarette smoking and sleep disturbance. Prev Med. 1994;23(3):328-334.

52. Phillips BA, Danner FJ. Cigarette smoking and sleep disturbance. Arch Intern Med. 1995;155(7):734-737.

53. McNamara JP, Wang J, Holiday DB, et al. Sleep disturbances associated with cigarette smoking. Psychol Health Med. Epub September 17, 2013.

54. Jaehne A, Loessl B, Bárkai Z, Riemann D, Hornyak M. Effects of nicotine on sleep during consumption, withdrawal and replacement therapy. Sleep Med Rev. 2009;13(5):363-377.

55. Levine MD, Bush T, Magnusson B, Cheng Y, Chen X. Smoking-related weight concerns and obesity: differences among normal weight, overweight, and obese smokers using a telephone tobacco quitline. Nicotine Tob Res. 2013;15(6):1136-1140. 
56. Williamson DF, Madans J, Anda RF, Kleinman JC, Giovino GA, Byers T. Smoking cessation and severity of weight gain in a national cohort. $N$ Engl J Med. 1991;324(11):739-745.

57. Krachman SL, Chatila W, Martin UJ, et al. Physiologic correlates of sleep quality in severe emphysema. COPD. 2011;8(3):182-188.

58. Kwon JS, Wolfe LF, Lu BS, Kalhan R. Hyperinflation is associated with lower sleep efficiency in COPD with co-existent obstructive sleep apnea. COPD. 2009;6(6):441-445.

59. Krachman SL, Chatila W, Martin UJ, et al. Effects of lung volume reduction surgery on sleep quality and nocturnal gas exchange in patients with severe emphysema. Chest. 2005;128(5):3221-3228.

60. Sateia MJ. Neuropsychological impairment and quality of life in obstructive sleep apnea. Clin Chest Med. 2003;24(2):249-259.

61. Engleman HM, Kingshott RN, Martin SE, Douglas NJ. Cognitive function in the sleep apnea/hypopnea syndrome (SAHS). Sleep. 2000;23(Suppl 4):S102-S108.

62. Yue W, Hao W, Liu P, Liu T, Ni M, Guo Q. A case-control study on psychological symptoms in sleep apnea-hypopnea syndrome. Can $J$ Psychiatry. 2003;48(5):318-323.

63. Di Marco F, Verga M, Reggente M, et al. Anxiety and depression in COPD patients: the roles of gender and disease severity. Respir Med. 2006;100(10): 1767-1774.

64. Doyle T, Palmer S, Johnson J, et al. Association of anxiety and depression with pulmonary-specific symptoms in chronic obstructive pulmonary disease. Int J Psychiatry Med. 2013;45(2):189-202.

65. Bady E, Achkar A, Pascal S, Orvoen-Frija E, Laaban JP. Pulmonary arterial hypertension in patients with sleep apnoea syndrome. Thorax. 2000;55(11):934-939.

66. Laks L, Lehrhaft B, Grunstein RR, Sullivan CE. Pulmonary hypertension in obstructive sleep apnoea. Eur Respir J. 1995;8(4):537-541.

67. Sanner BM, Doberauer C, Konermann M, Sturm A, Zidek W. Pulmonary hypertension in patients with obstructive sleep apnea syndrome. Arch Intern Med. 1997;157(21):2483-2487.

68. Chaouat A, Weitzenblum E, Krieger J, Oswald M, Kessler R. Pulmonary hemodynamics in the obstructive sleep apnea syndrome. Results in 220 consecutive patients. Chest. 1996;109(2):380-386.

69. Hawryłkiewicz I, Sliwiński P, Górecka D, Pływaczewski R, Zieliński J. Pulmonary haemodynamics in patients with OSAS or an overlap syndrome. Monaldi Arch Chest Dis. 2004;61(3):148-152.

70. Sharma B, Neilan TG, Kwong RY, et al. Evaluation of right ventricular remodeling using cardiac magnetic resonance imaging in co-existent chronic obstructive pulmonary disease and obstructive sleep apnea. COPD. 2013;10(1):4-10.

71. Tirlapur VG, Mir MA. Nocturnal hypoxemia and associated electrocardiographic changes in patients with chronic obstructive airways disease. N Engl J Med. 1982;306(3):125-130.

72. Patel D, Mohanty P, Di Biase L, et al. Safety and efficacy of pulmonary vein antral isolation in patients with obstructive sleep apnea: the impact of continuous positive airway pressure. Circ Arrhythm Electrophysiol. 2010;3(5):445-451.

73. Mehra R, Benjamin EJ, Shahar E, et al. Sleep Heart Health Study. Association of nocturnal arrhythmias with sleep-disordered breathing: The Sleep Heart Health Study. Am J Respir Crit Care Med. 2006;173(8): 910-916.

74. Gami AS, Pressman G, Caples SM, et al. Association of atrial fibrillation and obstructive sleep apnea. Circulation. 2004;110(4):364-367.

75. Kanagala R, Murali NS, Friedman PA, et al. Obstructive sleep apnea and the recurrence of atrial fibrillation. Circulation. 2003;107(20):2589-2594.

76. Guilleminault C, Connolly SJ, Winkle RA. Cardiac arrhythmia and conduction disturbances during sleep in 400 patients with sleep apnea syndrome. Am J Cardiol. 1983;52(5):490-494.

77. Ganga HV, Nair SU, Puppala VK, Miller WL. Risk of new-onset atrial fibrillation in elderly patients with the overlap syndrome: a retrospective cohort study. J Geriatr Cardiol. 2013;10(2):129-134.

78. Hoyert DL, Xu JQ. Deaths: Preliminary data for 2011. National vital statistics reports; vol 61 no 6. Hyattsville, MD: National Center for Health Statistics. 2012.
79. Celli BR, Cote CG, Marin JM, et al. The body-mass index, airflow obstruction, dyspnea, and exercise capacity index in chronic obstructive pulmonary disease. $N$ Engl J Med. 2004;350(10):1005-1012.

80. Lavie P, Herer P, Lavie L. Mortality risk factors in sleep apnoea: a matched case-control study. J Sleep Res. 2007;16(1):128-134.

81. Lavie P, Herer P, Peled R, et al. Mortality in sleep apnea patients: a multivariate analysis of risk factors. Sleep. 1995;18(3):149-157.

82. Scharf SM, Maimon N, Simon-Tuval T, Bernhard-Scharf BJ, Reuveni H, Tarasiuk A. Sleep quality predicts quality of life in chronic obstructive pulmonary disease. Int J Chron Obstruct Pulmon Dis. 2011;6:1-12.

83. Goldstein RS, Ramcharan V, Bowes G, McNicholas WT, Bradley D, Phillipson EA. Effect of supplemental nocturnal oxygen on gas exchange in patients with severe obstructive lung disease. $N$ Engl J Med. 1984;310(7):425-429.

84. Celli BR, MacNee W. ATS/ERS Task Force. Standards for the diagnosis and treatment of patients with COPD: a summary of the ATS/ERS position paper. Eur Respir J. 2004;23(6):932-946.

85. Myers KA, Mrkobrada M, Simel DL. Does this patient have obstructive sleep apnea? The Rational Clinical Examination systematic review. JAMA. 2013;310(7):731-741.

86. Epstein LJ, Kristo D, Strollo PJ Jr, et al. Adult Obstructive Sleep Apnea Task Force of the American Academy of Sleep Medicine. Clinical guideline for the evaluation, management and longterm care of obstructive sleep apnea in adults. J Clin Sleep Med. 2009;5(3):263-276.

87. Aurora RN, Chowdhuri S, Ramar K, et al. The treatment of central sleep apnea syndromes in adults: practice parameters with an evidencebased literature review and meta-analyses. Sleep. 2012;35(1):17-40.

88. Wellman A, Malhotra A, Jordan AS, Stevenson KE, Gautam S, White DP. Effect of oxygen in obstructive sleep apnea: role of loop gain. Respir Physiol Neurobiol. 2008;162(2):144-151.

89. Younes M, Ostrowski M, Thompson W, Leslie C, Shewchuk W. Chemical control stability in patients with obstructive sleep apnea. Am J Respir Crit Care Med. 2001;163(5):1181-1190.

90. Skatrud JB, Dempsey JA, Badr S, Begle RL. Effect of airway impedance on $\mathrm{CO} 2$ retention and respiratory muscle activity during NREM sleep. J Appl Physiol (1985). 1988;65(4):1676-1685.

91. Dempsey JA. Crossing the apnoeic threshold: causes and consequences. Exp Physiol. 2005;90(1):13-24.

92. Javaheri S, Smith J, Chung E. The prevalence and natural history of complex sleep apnea. J Clin Sleep Med. 2009;5(3):205-211.

93. Mulloy E, McNicholas WT. Theophylline improves gas exchange during rest, exercise, and sleep in severe chronic obstructive pulmonary disease. Am Rev Respir Dis. 1993;148(4 Pt 1):1030-1036.

94. Man GC, Champman KR, Ali SH, Darke AC. Sleep quality and nocturnal respiratory function with once-daily theophylline (Uniphyl) and inhaled salbutamol in patients with COPD. Chest. 1996;110(3):648-653.

95. Martin RJ, Pak J. Overnight theophylline concentrations and effects on sleep and lung function in chronic obstructive pulmonary disease. Am Rev Respir Dis. 1992;145(3):540-544.

96. Hein H, Behnke G, Jörres RA, Magnussen H. The therapeutic effect of theophylline in mild obstructive sleep Apnea/Hypopnea syndrome: results of repeated measurements with portable recording devices at home. Eur J Med Res. 2000;5(9):391-399.

97. Mulloy E, McNicholas WT. Theophylline in obstructive sleep apnea. A double-blind evaluation. Chest. 1992;101(3):753-757.

98. Martin RJ, Bartelson BL, Smith P, et al. Effect of ipratropium bromide treatment on oxygen saturation and sleep quality in COPD. Chest. 1999;115(5):1338-1345.

99. McNicholas WT, Calverley PM, Lee A, Edwards JC; Tiotropium Sleep Study in COPD Investigators. Long-acting inhaled anticholinergic therapy improves sleeping oxygen saturation in COPD. Eur Respir J. 2004;23(6):825-831.

100. Rasche K, Duchna HW, Lauer J, et al. Obstructive sleep apnea and hypopnea efficacy and safety of a long-acting beta2-agonist. Sleep Breath. 1999;3(4):125-130. 
101. Tashkin DP, Doherty DE, Kerwin E, et al. Efficacy and safety characteristics of mometasone furoate/formoterol fumarate fixed-dose combination in subjects with moderate to very severe COPD: findings from pooled analysis of two randomized, 52-week placebo-controlled trials. Int J Chron Obstruct Pulmon Dis. 2012;7:73-86.

102. Budhiraja R, Parthasarathy S, Budhiraja P, Habib MP, Wendel C, Quan SF. Insomnia in patients with COPD. Sleep. 2012;35(3):369-375.

103. Wood-Baker RR, Gibson PG, Hannay M, Walters EH, Walters JA. Systemic corticosteroids for acute exacerbations of chronic obstructive pulmonary disease. Cochrane Database Syst Rev. 2005;(1):CD001288

104. Niewoehner DE, Erbland ML, Deupree RH, et al. Effect of systemic glucocorticoids on exacerbations of chronic obstructive pulmonary disease. Department of Veterans Affairs Cooperative Study Group. $N$ Engl J Med. 1999;340(25):1941-1947.

105. Davies L, Angus RM, Calverley PM. Oral corticosteroids in patients admitted to hospital with exacerbations of chronic obstructive pulmonary disease: a prospective randomised controlled trial. Lancet 1999;354(9177):456-460.

106. de Jong YP, Uil SM, Grotjohan HP, Postma DS, Kerstjens HA, van den Berg JW. Oral or IV prednisolone in the treatment of COPD exacerbations: a randomized, controlled, double-blind study. Chest. 2007;132(6):1741-1747.

107. Aaron SD, Vandemheen KL, Hebert P, et al. Outpatient oral prednisone after emergency treatment of chronic obstructive pulmonary disease. N Engl J Med. 2003;348(26):2618-2625.

108. Decramer M, Lacquet LM, Fagard R, Rogiers P. Corticosteroids contribute to muscle weakness in chronic airflow obstruction. $\mathrm{Am} \mathrm{J}$ Respir Crit Care Med. 1994;150(1):11-16

109. Hopkinson NS, Man WD, Dayer MJ, et al. Acute effect of oral steroids on muscle function in chronic obstructive pulmonary disease. Eur Respir J. 2004;24(1):137-142.

110. Fishman A, Martinez F, Naunheim K, et al. National Emphysema Treatment Trial Research Group. A randomized trial comparing lungvolume-reduction surgery with medical therapy for severe emphysema. N Engl J Med. 2003;348(21):2059-2073.

111. Steens RD, Pouliot Z, Millar TW, Kryger MH, George CF. Effects of zolpidem and triazolam on sleep and respiration in mild to moderate chronic obstructive pulmonary disease. Sleep. 1993;16(4) 318-326.

112. Lacasse Y, Goldstein R, Lasserson TJ, Martin S. Pulmonary rehabilitation for chronic obstructive pulmonary disease. Cochrane Database Syst Rev. 2006;(4):CD003793.

113. Lan CC, Su CP, Chou LL, Yang MC, Lim CS, Wu YK. Association of body mass index with exercise cardiopulmonary responses in lung function-matched patients with chronic obstructive pulmonary disease. Heart Lung. 2012;41(4):374-381.

114. Ora J, Laveneziana P, Ofir D, Deesomchok A, Webb KA, O’Donnell DE. Combined effects of obesity and chronic obstructive pulmonary disease on dyspnea and exercise tolerance. Am J Respir Crit Care Med. 2009;180(10):964-971.

115. Ora J, Laveneziana P, Wadell K, Preston M, Webb KA, O’Donnell DE. Effect of obesity on respiratory mechanics during rest and exercise in COPD. J Appl Physiol (1985). 2011;111(1):10-19.

116. Ekman MJ, Klintenberg M, Björck U, Norström F, Ridderstråle M. Six-minute walk test before and after a weight reduction program in obese subjects. Obesity (Silver Spring). 2013;21(3):E236-E243.

117. Hulens M, Vansant G, Lysens R, Claessens AL, Muls E. Exercise capacity in lean versus obese women. Scand J Med Sci Sports 2001;11(5):305-309.

118. Vincent HK, Vincent KR, Lamb KM. Obesity and mobility disability in the older adult. Obes Rev. 2010;11(8):568-579.

119. Soler X, Diaz-Piedra C, Ries AL. Pulmonary rehabilitation improves sleep quality in chronic lung disease. COPD. 2013;10(2):156-163.

120. Sengul YS, Ozalevli S, Oztura I, Itil O, Baklan B. The effect of exercise on obstructive sleep apnea: a randomized and controlled trial. Sleep Breath. 2011;15(1):49-56.
121. Kline CE, Crowley EP, Ewing GB, et al. The effect of exercise training on obstructive sleep apnea and sleep quality: a randomized controlled trial. Sleep. 2011;34(12):1631-1640.

122. Norman JF, Von Essen SG, Fuchs RH, McElligott M. Exercise training effect on obstructive sleep apnea syndrome. Sleep Res Online. 2000;3(3):121-129.

123. Ackel-D'Elia C, da Silva AC, Silva RS, et al. Effects of exercise training associated with continuous positive airway pressure treatment in patients with obstructive sleep apnea syndrome. Sleep Breath. 2012;16(3):723-735.

124. Kline CE, Ewing GB, Burch JB, et al. Exercise training improves selected aspects of daytime functioning in adults with obstructive sleep apnea. J Clin Sleep Med. 2012;8(4):357-365.

125. Wang TY, Lo YL, Lee KY, et al. Nocturnal CPAP improves walking capacity in COPD patients with obstructive sleep apnoea. Respir Res. 2013;14(1):66

126. Nowiński A, Bieleń P, Jonczak L, Sliwiński P. [Influence of treatment with continuous positive airway pressure on respiratory muscle function and physical fitness in patients with obstructive sleep apnoea and overlap syndrome]. Pneumonol Alergol Pol. 2007;75(1):46-56. Polish.

127. Tuomilehto HP, Seppä JM, Partinen MM, et al. Kuopio Sleep Apnea Group. Lifestyle intervention with weight reduction: first-line treatment in mild obstructive sleep apnea. Am J Respir Crit Care Med. 2009;179(4):320-327.

128. Johansson K, Neovius M, Lagerros YT, et al. Effect of a very low energy diet on moderate and severe obstructive sleep apnoea in obese men: a randomised controlled trial. BMJ. 2009;339:b4609.

129. Johansson K, Hemmingsson E, Harlid R, et al. Longer term effects of very low energy diet on obstructive sleep apnoea in cohort derived from randomised controlled trial: prospective observational follow-up study. BMJ. 2011;342:d3017.

130. Calhoun DA, Jones D, Textor S, et al. Resistant hypertension: diagnosis, evaluation, and treatment. A scientific statement from the American Heart Association Professional Education Committee of the Council for High Blood Pressure Research. Hypertension. 2008;51(6):1403-1419.

131. Yancy CW, Jessup M, Bozkurt B, et al. Writing Committee Members. 2013 ACCF/AHA guideline for the management of heart failure: a report of the American College of Cardiology Foundation/American Heart Association Task Force on practice guidelines. Circulation 2013;128(16):e240-e319.

132. McLaughlin VV, Archer SL, Badesch DB, et al. ACCF/AHA. ACCF/ AHA 2009 expert consensus document on pulmonary hypertension: a report of the American College of Cardiology Foundation Task Force on Expert Consensus Documents and the American Heart Association: developed in collaboration with the American College of Chest Physicians, American Thoracic Society, Inc., and the Pulmonary Hypertension Association. Circulation. 2009;119(16):2250-2294.

133. Martin RJ, Sanders MH, Gray BA, Pennock BE. Acute and long-term ventilatory effects of hyperoxia in the adult sleep apnea syndrome. $\mathrm{Am}$ Rev Respir Dis. 1982;125(2):175-180.

134. Smith PL, Haponik EF, Bleecker ER. The effects of oxygen in patients with sleep apnea. Am Rev Respir Dis. 1984;130(6):958-963.

135. Gold AR, Schwartz AR, Bleecker ER, Smith PL. The effect of chronic nocturnal oxygen administration upon sleep apnea. Am Rev Respir Dis. 1986;134(5):925-929.

136. Loredo JS, Ancoli-Israel S, Kim EJ, Lim WJ, Dimsdale JE. Effect of continuous positive airway pressure versus supplemental oxygen on sleep quality in obstructive sleep apnea: a placebo-CPAP-controlled study. Sleep. 2006;29(4):564-571.

137. McEvoy RD, Pierce RJ, Hillman D, et al. Australian trial of noninvasive Ventilation in Chronic Airflow Limitation (AVCAL) Study Group. Nocturnal non-invasive nasal ventilation in stable hypercapnic COPD: a randomised controlled trial. Thorax. 2009;64(7): 561-566.

138. Tsolaki V, Pastaka C, Karetsi E, et al. One-year non-invasive ventilation in chronic hypercapnic COPD: effect on quality of life. Respir Med. 2008;102(6):904-911. 
139. Struik FM, Lacasse Y, Goldstein R, Kerstjens HM, Wijkstra PJ. Nocturnal non-invasive positive pressure ventilation for stable chronic obstructive pulmonary disease. Cochrane Database Syst Rev. 2013;6:CD002878.

140. Centers for Medicare \& Medicaid Services. Documentation checklist. Available from: https://www.cgsmedicare.com/jc/mr/PDF/ MR_checklist_RAD_E0470.pdf. Accessed March 4, 2014.
141. Stanchina ML, Welicky LM, Donat W, Lee D, Corrao W, Malhotra A. Impact of CPAP use and age on mortality in patients with combined COPD and obstructive sleep apnea: the overlap syndrome. J Clin Sleep Med. 2013;9(8):767-772.

\section{Publish your work in this journal}

The International Journal of COPD is an international, peer-reviewed journal of therapeutics and pharmacology focusing on concise rapid reporting of clinical studies and reviews in COPD. Special focus is given to the pathophysiological processes underlying the disease, intervention programs, patient focused education, and self management protocols.

\section{Dovepress}

This journal is indexed on PubMed Central, MedLine and CAS. The manuscript management system is completely online and includes a very quick and fair peer-review system, which is all easy to use. Visit $\mathrm{http} / / / \mathrm{www}$.dovepress.com/testimonials.php to read real quotes from published authors.

Submit your manuscript here: http://www.dovepress.com/international-journal-of-copd-journal 